\title{
Recobrimentos e períodos de armazenamento na conservação pós-colheita de estacas de cordiline (Cordyline rubra Hügel) ${ }^{(1)}$
}

\author{
NELSON MAMORU SAKAMOTO(2), MARNEY PASCOLI CEREDA(3), \\ ROBERVAL DE CASSIA RIBEIRO(4)
}

\begin{abstract}
RESUMO
O Brasil possui grande potencial exportador de flores e plantas ornamentais, e o emprego de técnicas simples de armazenamento poderia viabilizar o transporte por modais que não o aéreo, reduzindo custos, podendo prolongar a vida útil dos produtos. Este trabalho compara cinco tipos de recobrimento em estacas de Cordyline rubra Hügel (película amilácea, pasta de parafina no ápice, pasta de parafina no ápice e vermiculita umedecida na base, saco plástico ou sem recobrimento) e diferentes períodos de armazenamento (30,60, 90 ou 120 dias), a fim de reduzir sua atividade biológica, perda de água e ataque de patógenos. Foi escolhida esta espécie por ser muito apreciada como planta ornamental pela beleza de suas folhas e exportada na forma de estacas de diferentes tamanhos. O experimento foi conduzido nas dependências do Departamento de Produção Vegetal da Escola Superior de Agricultura "Luiz de Queiroz", Universidade de São Paulo, no município de Piracicaba, Estado de São Paulo. Foram utilizadas 300 estacas com $30 \mathrm{~cm}$ de comprimento por $3 \mathrm{~cm}$ de diâmetro. Cada tratamento foi composto por 15 estacas pré-tratadas (tipos de recobrimento), submetidas a períodos de armazenamento (30, 60, 90 ou 120 dias) sob refrigeração e temperatura ambiente, totalizando 60 estacas. Após o armazenamento, foram cortados $3 \mathrm{~cm}$ da base de cada estaca, em seguida, tratadas com ácido indolbutírico a $10.000 \mathrm{mg} / \mathrm{L}$ e colocadas em leito de enraizamento de areia grossa. Após 90 dias, foram avaliados os seguintes parâmetros: porcentagem de desenvolvimento, número e massa fresca e seca de brotos e raízes. Observou-se que os menores períodos de armazenamento proporcionam melhor desenvolvimento das estacas. Os tipos de recobrimento que melhor conservaram as estacas, em ordem decrescente de resultados, foram o saco plástico, parafina no ápice e vermiculita umedecida na base, parafina no ápice, película de amido e sem recobrimento. Conclui-se que o método mais prático foi embalar as estacas em sacos plásticos por não necessitar de fonte de calor para o preparo da película. Quanto maiores os períodos de armazenamento, menores os desenvolvimentos de brotos e raízes.
\end{abstract}

Palavras-chave: Cordyline rubra, pós-colheita, estacas, planta ornamental, películas flexíveis.

\section{ABSTRACT \\ Types of coating and periods of storage on the postharvest conservation of Cordyline rubra Hügel cuttings}

Brazil has a great potential to increase its export of flowers and other ornamental plants and the use of simple storage techniques, would enable the transport through other means than airplanes, consequently reducing costs and adding extra shelf life to the product. This work was aimed at comparing five types of coating of Cordyline rubra Hügel cuttings (starch film, paraffin paste at the apex, paraffin past at the apex associated with moist vermiculite at the base of the cuttings, plastic bags or no coating) and different lengths of time on storage (30, 60, 90 or 120 days), under refrigeration or room conditions in order to reduce their biological activity, water loss and pathogen attacks. This specie is very appreciated as an ornamental plant due to the beauty of their foliage and is exported as cuttings of different sizes. The experiment was carried out at the Department of Plant Production at "Luiz de Queiroz" College of Agriculture, University of Sao Paulo, in Piracicaba City, Sao Paulo State, Brazil. A total of 300 cuttings were used, each measuring $30 \mathrm{~cm}$ by $3 \mathrm{~cm}$ diameter. Each treatment was comprised of 15 pre-coated cuttings (types of coating), stored at different periods (30.60, 90 or 120 days), summing up 60 cuttings. After storage, each cutting had 3 em excised from its base, prior to being treated with Indol Butiric Acid 10,000 mg/L and placed at grit as rooting beds. After 90 days, the following parameters were assessed: percentage of cuttings showing growth and development, number and fresh and dry matter of the shoots and roots. It was observed that the shorter the storage periods the better the cutting sprouting. The types of coatings which best supported the longevity of the cuttings, in decrease order, were: plastic bag, paraffin paste at the apex and moist vermiculite at the base, paraffin on the apex, starch film and no coating. Such results allow concluding that the most practical coating technique was found to be the use of plastic bags, which did not need heating for the film preparing. The longer the storage time the smallest the number of viable cuttings.

Keywords: Cordyline rubra, postharvest, cuttings, ornamental plant, flexible film.

\footnotetext{
(1) Parte da Dissertação de Mestrado do Primeiro autor. Recebido para publicação em 26/08/2009 e aceito em 12/05/2011.

(2) Mestrando em Fitotecnia, ESALQ/USP - Email: nelson.sakamoto@sakata.com.br

(3) Professora e Pesquisadora do Centro de Tecnologia e Análise do Agronegócio- UCDB, Campo Grande, MS Avenida Tamandaré, 8000, CeTeAgro/

UCDB, Instituto São Vicente, Campo Grande - MS, 79 117-900. - Email: cereda@ucdb.br

(4).Professor do Departamento de Fitotecnia, ESALQ/USP - Email: roberval_ribeiro@hotmail.com
} 


\section{INTRODUÇÃO}

Segundo VIEIRA e BORGES (2011), a floricultura vem ganhando cada vez mais espaço no país por várias razões, entre as quais o aumento da demanda internacional por produtos diferenciados como as flores tropicais e inovações tecnológicas. O crescimento da demanda impacta positivamente na produção do setor de floricultura, na geração de emprego e na pauta de exportação.

$\mathrm{O}$ setor de flores e plantas ornamentais abrange uma diversidade de serviços e produtos. O cultivo e exploração de plantas ornamentais incluem as flores de corte frescas ou secas, plantas em vaso, folhagens frescas ou desidratadas, estacas, enxertos, alporques, substratos de enraizamento, desde a condução de mudas e produção de arbustos a árvores de grande porte (SMORIGO, 1999).

Segundo BATALHA e BUAINAIN (2007), o maior produtor, consumidor e exportador de flores e plantas ornamentais do Brasil é o Estado de São Paulo, que detém $74,5 \%$ da produção nacional. Os principais polos no Estado são Atibaia, Grande São Paulo, Dutra, Vale do Ribeira, Paranapanema e Campinas. Depois do Estado de São Paulo, os principais produtores de flores e plantas ornamentais são Santa Catarina, Pernambuco, Alagoas, Ceará, Rio Grande do Sul, Minas Gerais, Rio de Janeiro, Paraná, Goiás, Bahia, Espírito Santo, Amazonas e Pará.

Em relação às exportações de produtos da floricultura brasileira, entre 1996 e 2006 houve crescimento de 320\% no valor exportado, em tonelada de flores, passando de 361 toneladas no ano base para 1157 toneladas em 2006. Esse volume exportado foi destinado principalmente aos Estados Unidos, Países Baixos, Portugal, Canadá e Alemanha. O valor acumulado atingiu US\$2.895 milhões, entre 2007 e julho de 2008, considerando as exportações de flores de corte (buquês) e folhagens (musgos, liquens e folhagens) (AGRIANUAL, 2003, 2009).

Uma das principais características da produção de flores e plantas ornamentais é ser uma atividade típica de pequenos produtores. Embora seja difícil precisar os números que envolvem a produção de flores e plantas ornamentais no Brasil, em virtude da inconsistência das informações disponíveis, as estimativas são de que a área envolvida nessa atividade, em 1999, era de, aproximadamente, 4.900 ha. Deste total, menos de $26 \%$ se refere a cultivos em estufas e $3 \%$, a cultivos em telas. A maior parte da produção, 71\%, é cultivo a céu aberto. Mesmo constituído por pequenas propriedades, o setor gera para os produtores um faturamento estimado em 322,3 milhões de reais/ano. O setor é responsável pela geração de aproximadamente 50 mil empregos, dos quais $45 \%$ estão localizados na produção, $6 \%$ na distribuição, $45 \%$ no comércio e $4 \%$ em atividades de apoio. A produção brasileira de flores e plantas ornamentais, inicialmente concentrada no Estado de São Paulo, tem se expandido para todo o país, com cultivos nos estados do Rio de Janeiro, Minas Gerais, Santa Catarina, Paraná, Rio Grande do Sul, Bahia, Alagoas, Pernambuco, Ceará e, também, na região norte. O Brasil possui notórias vantagens comparativas para ampliar a produção de flores, bastando observar os microclimas privilegiados, a disponibilidade de terra, água, mão de obra e tecnologias agronômicas disponíveis. Apesar das vantagens comparativas, o setor de flores e folhagens ornamentais necessita cada vez mais de ações articuladas, capazes de dotar o país de condições para uma produção competitiva, quantitativa e qualitativamente. A transformação das potencialidades em oportunidades de negócio efetivas está condicionada ao rompimento de importantes pontos de estrangulamento localizados ao longo da cadeia produtiva que objetivem dotar o setor florícola nacional de capacidade técnica e organizacional capaz de aumentar significativamente a participação brasileira no mercado internacional de forma organizada, profissional, competente e competitiva (IBRAFLOR, 2011).

Devido às barreiras de ordem fitossanitárias impostas pela maioria dos países quanto à importação de material vegetal contendo solo, ele é normalmente exportado na forma de flores cortadas (rosas), bulbos (gladíolo), mudas com raiz nua (violeta), cultura in vitro (orquídeas) ou ainda na forma de estacas (dracenas).

Apesar de a maioria das estacas comercializadas ser destinada a produtores de plantas envasadas, grande parte dos varejistas que operam no Mercado Flutuante de Flores em Amsterdã - Holanda comercializam estacas de Dracaena spp. (dracenas - as mais comercializadas), Bougainvillea spp. (primaveras), Polyscias spp. (árvores da felicidade), filhotes de Beaucarnea spp. (pata de elefante) e Cycas spp. (palmeira cicas) parcialmente recobertos por parafina. O preço é bem menor quando comparado com plantas envasadas já formadas.

A empresa Plantas Exóticas do Brasil Agri Floricultura Ltda., localizada em Juquiá-SP, vem explorando este mercado. É dela a afirmação de que, apesar do recente aumento das exportações da empresa para o Mercosul, o Brasil tem sofrido grande concorrência de países como Costa Rica e Guatemala nos mercados norte-americano e europeu. Nestes últimos anos, outros países produtores emergentes também têm se especializado na produção de folhagens tropicais, como Sri Lanka, Tailândia, Malásia e também alguns países do continente africano, como Quênia e Zimbábue.

No transporte internacional de flores de corte, predominam o aéreo e o rodoviário e, por se tratar de um produto perecível, há diversos riscos envolvidos. Se houver qualquer atraso no transporte, podem ocorrer perdas para o exportador, que dificultam ainda mais a entrada do produto em países estrangeiros (ANEFALOS, 2004).

O emprego de técnicas simples de armazenamento, dentro da realidade do produtor, poderia viabilizar os transportes fluvial e marítimo, que, apesar de mais baratos, exigem períodos de armazenamento razoavelmente longos. Além disso, tais técnicas poderiam prolongar a vida de prateleira dessas estacas junto ao mercado varejista, criando um diferencial de qualidade do produto brasileiro em relação aos concorrentes.

A pesquisa comparou cinco tipos de recobrimento em estacas de Cordyline rubra Hügel, visando a reduzir

(1) SAKAMOTO, N.M. como co-proprietário da empresa Plantas Exóticas do Brasil Agri Floricultura Ltda., de Juquiá - SP, em 2011. 
sua atividade biológica e, consequentemente, a perda de umidade, esperando estender dessa forma o período de armazenamento das estacas.

\section{MATERIAL E MÉTODOS}

O experimento foi conduzido nas dependências do Departamento de Produção Vegetal da Escola Superior de Agricultura "Luiz de Queiroz"/USP.

O material vegetal foi fornecido pela empresa Plantas Exóticas do Brasil Agri Floricultura Ltda., de Juquiá - SP.

As plantas matrizes, de onde se obtiveram as estacas, foram cultivadas a pleno sol, com idades variando entre 4 e 8 anos, em condições de elevada umidade relativa do ar e sob irrigação por aspersão.

O clima da região é do tipo tropical e subtropical quente e úmido. A temperatura média é de $28^{\circ} \mathrm{C}$, no verão podendo ultrapassar $37^{\circ} \mathrm{C}$ e no inverno, chegar abaixo de $10^{\circ} \mathrm{C}$. O relevo é fortemente acidentado, com declividade de $20^{\circ}$ a $70^{\circ}$. O solo é constituído por latossolo amarelo, pobre e ácido (JUQUIÁ: INFORMAÇÕES, 2005).

\subsection{Instalação e condução do experimento}

Foram utilizadas 300 estacas sem folhas, cortadas em serra circular, com comprimento de $30 \mathrm{~cm}$ e diâmetro de $3,0 \mathrm{~cm}$. As estacas foram obtidas da porção mediana dos ramos, descartando-se as porções apicais e basais.

As estacas, previamente submetidas à desinfestação, foram separadas em 5 lotes de 60 estacas, sendo cada lote submetido a um dos tipos de recobrimento que se seguem:

a) recobertas com película de amido comercial de mandioca a 3\%, adquirido no mercado;

b) recobrimento da parte apical das estacas com pasta feita de parafina fundida e cimento Portland (5:2 em peso);

c) com porção apical tratada com pasta de parafina fundida e cimento Portland (5:2 em peso) e parte basal inserida em um saquinho plástico contendo $10 \mathrm{~g}$ de vermiculita umedecida;

d) acondicionadas em saco plástico transparente e fechado; e

e) testemunha, sem recobrimento.

Cada tratamento foi composto de 15 estacas, submetidas a diferentes condições de armazenamento (PRYOR e STEWART, 1963) ambiente $\left(22\right.$ a $32^{\circ} \mathrm{C}$ com $80 \% \mathrm{UR})$ ou refrigerada $\left(10^{\circ} \mathrm{C}\right.$ com $\left.90 \% \mathrm{UR}\right)$, tempo (30, 60,90 ou 120 dias) e tipos de recobrimento (AM, PV, PA, SP e SR), totalizando 60 estacas por pré-tratamento. Em todos os tratamentos, as estacas foram mantidas na posição horizontal e no escuro.

Ao final do período de 30, 60, 90 ou 120 dias de armazenamento, as estacas foram etiquetadas e transferidas aleatoriamente para o leito de areia grossa para enraizamento, após as suas partes basais serem cortadas com o uso de uma serra circular e tratadas com ácido indolbutírico (AIB) a $10.000 \mathrm{mg} / \mathrm{L}$, sob as mesmas condições adotadas para o tratamento testemunha.

\subsection{Obtenção e preparo da suspensão filmogênica de amido}

$\mathrm{O}$ amido de mandioca comercial foi obtido no mercado local, e a suspensão filmogênica preparada, segundo HENRIQUE et al. (2007). Para o preparo do recobrimento, $3 \%$ de amido de mandioca foi disperso manualmente em água e aquecido a $70^{\circ} \mathrm{C}$ por 20 minutos, com agitação constante. Após o resfriamento do gel à temperatura ambiente $\left(25^{\circ} \mathrm{C}\right)$, o produto foi aplicado pela imersão das estacas, feita a drenagem do excesso por 3 minutos, seguida de secagem natural.

\subsection{Delineamento estatístico}

O delineamento experimental foi o inteiramente casualizados no esquema fatorial 4 X5. Foram empregados 4 períodos de armazenamento (30, 60, 90 ou 120 dias) e 5 tipos de recobrimento (amido de mandioca, parafina no ápice, parafina no ápice e vermiculita umedecida na base, saco plástico e apenas armazenadas na posição horizontal), com 15 repetições (estacas).

\subsection{Análises físicas}

A avaliação do enraizamento e da brotação das estacas foi programada para ser feita 90 dias após serem colocadas em leito de enraizamento de areia grossa.

Para coleta e análise dos resultados, foram considerados as porcentagens de estacas brotadas e/ou enraizadas, o número de brotos e raízes por estaca e a massa fresca de brotos e raízes. A massa seca de brotos e raízes foi avaliada após a estabilização da massa em estufa a $65^{\circ} \mathrm{C}$ (cerca de 4 dias).

\subsection{Análises estatísticas}

Os dados foram analisados pelo teste $\mathrm{F}$, posteriormente os tratamentos foram comparados por um teste de médias, tendo sido utilizado o software estatístico SAS para as análises.

\section{RESULTADOS E DISCUSSÃO}

As Tabelas 1 e 2 apresentam as análises das médias do número de brotos e raízes, respectivamente, em estacas de C. rubra, além da massa fresca e seca dos mesmos, relacionados com condições de armazenamento ambiente $\left(22\right.$ a $32^{\circ} \mathrm{C}$ com $\left.80 \% \mathrm{UR}\right)$ ou refrigerado $\left(10^{\circ} \mathrm{C}\right.$ com $90 \% \mathrm{UR})$, tempo $(30,60,90$ ou 120 dias) e tipos de recobrimento (AM, PV, PA, SP e SR).

Relacionando o período de armazenamento com os tipos de recobrimento empregados nas estacas, pode-se observar que, para todos os tipos de recobrimento empregados, o fator tempo de armazenamento foi importante no posterior desenvolvimento das estacas. Quanto menor o período de armazenamento, mais vigorosos foram a brotação e o enraizamento das estacas. No experimento, o período de 30 dias foi o que apresentou os melhores resultados, tanto para brotação como para enraizamento. $\mathrm{O}$ efeito para todos os tipos de recobrimento não diferiu quanto ao número de brotos e raízes. Entretanto, o efeito para a massa fresca e seca das raízes diferenciou o recobrimento SP como o que proporcionou os melhores resultados no enraizamento. Para fins de comparação, considerou-se a massa seca do recobrimento SP como 100\% aos 30 dias e em condição refrigerada (Tabela 1). Nestas condições, destaca-se a superioridade deste revestimento, uma vez que os demais 
variaram de 62 a $55 \%$. O segundo melhor revestimento seria o PA com $62 \%$, seguido pelo AM com $58 \%$, PV com $57 \%$ e, finalmente, pelo SR com 55\%.

Quando a condição de armazenamento das estacas foi em temperatura ambiente, as variações diferiram na ordem de eficiência. O segundo melhor recobrimento AM proporcionou $54 \%$ da massa seca obtida com o revestimento SP, seguido dos revestimentos PV e SR, ambos com 50\%.

Os resultados obtidos aos 30 dias concordam com aqueles encontrados por vários autores, entre eles, FLINT e McGUIRE (1960), POOLE e CONOVER (1992), REIS (1998) e SOUZA (1990), que relatam que, com o aumento do período de armazenamento, a tendência é o percentual de enraizamento diminuir.

Aos 60 e 90 dias de armazenamento, os recobrimentos que se destacaram foram $\mathrm{PV}$ e $\mathrm{SP}$, tanto em número de brotos como em número de raízes, assim com suas respectivas massas fresca e seca.

Aos 120 dias, nota-se que não houve diferenças significativas entre os tipos de recobrimento, embora PV e SP tenham proporcionado melhores resultados do que os demais para número de raízes e massa fresca e seca, respectivamente, com queda desses valores para todos os recobrimentos.

Os resultados encontrados com o recobrimento com parafina confirmam aqueles descritos por CHITARRA e CHITARRA (1990) quanto à redução na perda de água e diminuição no enrugamento do material. CARDOSO (1961) encontrou resultados semelhantes para estacas de seringueira que mantiveram suas melhores características quando recobertas com parafina. SILVA e LOPES (1993), em experimento de conservação de ramas de batata-doce (Ipomoea batatas), observaram que o recobrimento com parafina não impediu a troca gasosa entre as ramas e o meio ambiente, pois foi observada uma crescente perda de massa no decorrer do período de armazenamento, mais lenta para as estacas recobertas em relação às estacas sem recobrimento, mantendo assim a qualidade fisiológica do material. Os autores observaram também que as estacas armazenadas por 16 dias, sem recobrimento, perderam a capacidade de gerar novas plantas, enquanto o recobrimento com parafina permitiu manter suas qualidades fisiológicas.

No presente trabalho, o método que empregou a embalagem das estacas em saco plástico, quando combinado com o armazenamento em ambiente refrigerado (Tabela 1), apresentou bons resultados, permitindo que as estacas permanecessem armazenadas por períodos longos de tempo (no caso, 120 dias) e ainda assim, enraizassem.

Resultados semelhantes foram encontrados por REIS (1998) em experimento com estacas de Polyscias guilfoylei Bailey, envolvendo diversos tipos de recobrimentos, entre eles, a embalagem em saco plástico, recobrimento da parte apical com pasta de parafina fundida e base em vermiculita umedecida, que obtiveram destaque por manterem a qualidade das estacas, promovendo um bom enraizamento após períodos de armazenamento de 30, 60 e 90 dias.

FLINT e MCGUIRE (1960) conseguiram até $100 \%$ de sobrevivência das estacas de várias espécies de ornamentais - Forsythia intermedia' Lynwood Gold', Juniperus chinensis glauca Hetzi, Pachistima canbyi, Thuja orientalis aurea nana, Weigela 'Vanicekii', Hibiscus syriacus 'Lady
Stanley' e Rhododendron obtusum 'Sherwood Red' - após 4 meses de armazenamento com a utilização de saco plástico, mas quando o armazenamento foi estendido para 6 meses, houve declínio.

REIS et al.(1997) recomendam ainda o uso da embalagem em sacos plásticos para estacas de Polyscias guilfoylei Bailey pela sua praticidade e por não diferirem estatisticamente do recobrimento com parafina. Ainda pela praticidade, produtores de mudas de crisântemo utilizam rotineiramente saco plástico como embalagem.

Observou-se no presente trabalho que o uso da película à base de amido de mandioca não foi satisfatório mesmo em período curto de 30 dias de armazenamento, não tendo, por vezes o tratamento se diferenciado das estacas testemunhas sem recobrimento. Em pesquisa realizada com o mesmo tipo de recobrimento, KAVAMURA et al. (2002) mostraram que hastes de rosa recobertas com películas de amido de mandioca modificado para ser solúvel em água (CMA) apresentaram melhores resultados de pós-colheita quando em condições ambiente, enquanto em ambiente refrigerado as hastes apresentaram melhores resultados com o uso da película à base de cera de carnaúba.

$\mathrm{O}$ uso de películas de amido também não foi eficiente nos resultados de FERRAZ e CEREDA (2007) com hastes florais de rosa. Os autores observaram que as hastes duraram apenas 4 dias em condições de comercialização e assim mesmo não diferiram da testemunha não tratada. Em ambos os casos, o processo de senescência das flores continuou normalmente, consumindo principalmente açúcares e ocasionando perda de massa e redução no teor de peroxidase.

A explicação para o mau comportamento do gel de amido como filme e película protetora é fornecida por HENRIQUE et al. (2007), que esclarecem que o material é pobre barreira para vapor d'água, embora seja eficiente barreira para gordura. Apenas alterações nestas propriedades feitas para filmes derivados do petróleo poderão viabilizar seu uso como barreira.

Com a seleção dos tipos de recobrimento de melhor facilidade de uso, melhor desempenho, aliados ao acondicionamento em baixas temperaturas, seria possível transportar as estacas de C. rubra por outros modais que não o aéreo, como é realizado atualmente em sua exportação, reduzindo custos, mantendo suas características e atendendo ao consumidor da melhor forma possível.

\section{CONCLUSÕES}

O armazenamento sob refrigeração proporcionou melhores resultados que as estacas armazenadas sob temperatura ambiente. Em ambos os casos, todos os recobrimentos poderiam ser recomendados para tempo de armazenamento de até 30 dias, por apresentaram bom enraizamento e desenvolvimento da parte aérea. Aos 120 dias de armazenamento, apenas o recobrimento com parafina (PV) pode ser recomendado com bons resultados.

Os melhores resultados foram sempre obtidos com o emprego de sacos plásticos ou parafina no ápice e vermiculita umedecida na base das estacas, pois a qualidade das estacas foi mantida por mais tempo. Visando 
a uma maior praticidade, o recobrimento das estacas com saco plástico é recomendado em relação aos demais recobrimentos que exigiram o uso de uma fonte de calor ou apresentam dificuldade no processo de embalagem individual.

\section{REFEREÊNCIAS}

AGRIANUAL Flores. São Paulo: FNP, 2004, 2005, 2006, 2007, 2008, 2009. (FNP Consultoria \& Comércio). Disponível em: <http://www.fnp.com.br/publicacoes/ anuarios/agrianual $>$. Acesso em 02 janeiro 2011.

ANEFALOS, L. C. Modelo insumo-produto como instrumento de avaliação econômica da cadeia de suprimentos: O caso da exportação de flores de corte. Piracicaba. Piracicaba: Universidade de São Paulo, 2004. 210p. Tese de Doutorado. Escola Superior de Agricultura "Luiz de Queiróz".

BATALHA, M. O.; BUAINAIN, A.M. Cadeias produtivas de flores e mel. Brasília: IICA: MAPA/SPA, 2007.

CARDOSO, M. Conservação de hastes de seringueira destinadas à enxertia. Bragantia, Campinas, v.20, p.53-56, ago., 1961 .

Chitarra, M. I. F; ChITARrA, A. B. Pós-Colheita de Frutos e Hortaliças: Fisiologia e Manuseio. Lavras: ESAL/FAEP, 1990. 320p.

FERRAZ, M. V.; CEREDA, MP. Utilização de películas amiláceas na conservação pós-colheita de rosa. Revista Científica Eletrônica de Agronomia, Garça, v. 16, p. 1219,2009

FLINT, H. L.; McGUIRE. Overwinter refrigerated storage of rooted cuttings. Rhode Island Nurseryman's Newsletter, n.3, p.5-8, 1960.

HENRIQUE, C.M.; TEOFILO, R.L. ; SABINO, L.; FERREIRA, M.M.C. ; CEREDA, M.P. Classification of cassava starch films by physicochemical properties and water vapor permeability quantification by FTIR and PLS. Journal of Food Science, Chicago, v. 72, n. 4, p. 184-189, 2007.

IBRAFLOR. Floricultura no Brasil: Apontamentos mais relevantes sobre o papel socioeconômico recente da atividade. Disponível em: < www.ibraflor.org.br $>$. Acesso em: 02 de julho de 2011.

JUNQUEIRA, A. H.; PEETZ, M. S. Os polos de produção de flores e plantas ornamentais no Brasil: Uma análise do potencial exportador. Revista Brasileira de Horticultura Ornamental, Campinas, v.8, n.1/2, p.25-47, 2002.
JUQUIÁ: Informações. http://www.valedoribeira.com.br/ iuquia/informacoes/index.asp, 2005.

KAVAMURA, H. E.; SAKAMOTO, N. M.; OLIVEIRA, M. 1. G.; RIBEIRO, R. C. S.; CEREDA, M. P. Películas flexíveis e seus efeitos na conservação pós-colheita de hastes florais de rosa armazenadas sob diferentes períodos de refrigeração. Piracicaba, 2002.32p. Relatório (Estágio Supervisionado) - Escola Superior de Agricultura "Luiz de Queiroz". Universidade de São Paulo.

POOLE, R. T.; CONOVER, C. A. Effect of storage position on growth of Dracaena fragrans "Massangeana" cane. Proceedings of the Interamerican Society for Tropical Horticulture, v.3 6, p.118-122, 1992.

PRYOR, R. L.; STEWART, R L. Storage of unrooted azalea cuttings. American Society for Horticultural Science, v.82, p.483-484, 1963.

REIS, S. D. A. Efeitos dos tratamentos e do armazenamento no enraizamento de estacas de Polyscias guilfoylei Bailey (Árvore da felicidade) e de Bougainvillea spectabilis Willd. (primavera). Ilha Solteira, 1998. 92p. Monografia (Graduação) Universidade Estadual Paulista "Júlio de Mesquita Filho".

REIS, S. D. A; RIBEIRO, R. C. S.; FABRI, E. G.; BOLIANI, A.C.; SOUZA, M. A. L. B. Armazenamento de estacas de árvore da felicidade (Polyscias guilfoylei). In: CONGRESSO BRASILEIRO DE FLORICULTURA E PLANTAS ORNAMENTAIS, 11, Belém, 1997. Anais, Sociedade Brasileira de Plantas Ornamentais, Belém, 1997.

SILVA, J. B. C.; LOPES, C. A. Uso de parafina na conservação de ramas de batata-doce. Horticultura Brasileira, Campinas, v.11, n.1 ,p.25-26, 1993.

SMORIGO, J. N. Os sistemas de distribuição de flores e plantas ornamentais: uma aplicação da economia dos custos de transação. In:WORKSHOP BRASILEIRO DE GESTÃO DE SISTEMAS AGROALIMENTARES, 2. Anais... PENSA/FEA/USP Ribeirão Preto, 1999.

SOUZA, L. H. Armazenamento de hastes de portaenxerto de seringueiras (Hevea brasiliensis, Muell \& Arg.) "clone RRIM 600". Lavras: Escola Superior de Agricultura de Lavras, 1990. 43p. Dissertação (Mestrado).

VIEIRA, G.C.; BORGES, A.C.G. Barreiras para ingressar no comércio externo de flores: o estudo de caso de uma empresa produtora do Estado de São Paulo. 2009 . Disponível em <http://prope.unesp.br/xxi cic/27_31100779817.pdf>. Acesso em: 02 de janeiro 2011. 
Tabela 1. Médias do número de brotos desenvolvidos e suas respectivas massas de matéria fresca e seca, em gramas, observadas em estacas de C. rubra, tratadas com 5 tipos de recobrimento e armazenadas por 30, 60, 90 ou 120 dias sob condições refrigeradas $\left(10^{\circ} \mathrm{C} ; 90 \% \mathrm{UR}\right)$.

\begin{tabular}{|c|c|c|c|c|c|}
\hline \multirow[b]{2}{*}{ Parâmetros } & \multirow[b]{2}{*}{$\begin{array}{l}\text { Tipo de } \\
\text { recobrimento }\end{array}$} & \multicolumn{4}{|c|}{ Período de armazenamento (dias) } \\
\hline & & 30 & 60 & 90 & 120 \\
\hline \multirow[t]{5}{*}{ Número de brotos } & $\mathrm{AM}$ & $2,93 \mathrm{bcC}$ & $0,96 \mathrm{bcC}$ & $0,76 \mathrm{cC}$ & $0,00 \mathrm{cB}$ \\
\hline & PV & $3,26 \mathrm{aA}$ & $3,50 \mathrm{aA}$ & $3,03 \mathrm{aAB}$ & $2,50 \mathrm{aA}$ \\
\hline & PA & $3,50 \mathrm{aA}$ & $2,30 \mathrm{abAB}$ & $1,46 \mathrm{bcBC}$ & $0,03 \mathrm{cB}$ \\
\hline & SP & $3,90 \mathrm{aA}$ & $2,66 \mathrm{abAB}$ & $3,16 \mathrm{abA}$ & $1,60 \mathrm{bAB}$ \\
\hline & SR & $3,96 \mathrm{aA}$ & $1,43 \mathrm{bBC}$ & $0,56 \mathrm{bC}$ & $0,00 \mathrm{bB}$ \\
\hline \multirow[t]{5}{*}{ Massa Seca (g) } & $\mathrm{AM}$ & $7,48 \mathrm{aB}$ & $1,86 b \mathrm{bB}$ & $0,38 \mathrm{bB}$ & $0,00 \mathrm{bA}$ \\
\hline & PV & $7,40 \mathrm{abB}$ & $9,53 \mathrm{aA}$ & $6,02 \mathrm{abA}$ & $4,20 \mathrm{bA}$ \\
\hline & PA & $8,04 \mathrm{aB}$ & $5,22 \mathrm{abAB}$ & $2,45 \mathrm{bcAB}$ & $0,01 \mathrm{cA}$ \\
\hline & SP & $12,96 \mathrm{aA}$ & $6,42 \mathrm{bA}$ & $6,63 \mathrm{bA}$ & $3,19 \mathrm{bA}$ \\
\hline & SR & $7,08 \mathrm{aB}$ & $2,02 \mathrm{bB}$ & $0,27 \mathrm{bB}$ & $0,00 \mathrm{bA}$ \\
\hline \multirow[t]{5}{*}{ Massa Fresca (g) } & $\mathrm{AM}$ & $8,63 \mathrm{aA}$ & $2,36 \mathrm{bB}$ & $1,46 b C$ & $0,00 \mathrm{bA}$ \\
\hline & PV & $9,30 \mathrm{abA}$ & $9,63 \mathrm{abA}$ & $11,06 \mathrm{aA}$ & $5,40 \mathrm{bA}$ \\
\hline & PA & $10,20 \mathrm{aA}$ & $5,96 \mathrm{aAB}$ & $4,33 \mathrm{abBC}$ & $0,03 \mathrm{bA}$ \\
\hline & SP & $16,33 \mathrm{aA}$ & $5,70 \mathrm{bAB}$ & 7,93abAB & $2,86 \mathrm{bA}$ \\
\hline & SR & $9,93 \mathrm{aA}$ & $3,23 \mathrm{bB}$ & $0,53 \mathrm{bC}$ & $0,00 \mathrm{bA}$ \\
\hline
\end{tabular}

AM - amido de mandioca; PV - parafina; PA- parafina no ápice; SP - saco plástico; SR - sem recobrimento.

Médias seguidas de mesma letra (letras minúsculas na horizontal; letras maiúsculas na vertical) não diferem entre si ao nível de 5\% de probabilidade pelo Teste de Tukey. 
Tabela 2. Médias do número de raízes desenvolvidas e suas respectivas massafresca e seca, em gramas, observadas em estacas de C. rubra, tratadas com 5 tipos de recobrimento e armazenadas por 30, 60, 90 ou 120 dias sob condições ambiente $\left(22\right.$ a $\left.32^{\circ} \mathrm{C} ; 80 \% \mathrm{UR}\right)$.

\begin{tabular}{|c|c|c|c|c|c|}
\hline \multirow[b]{2}{*}{ Parâmetros } & \multirow[b]{2}{*}{$\begin{array}{c}\text { Tipo de } \\
\text { recobrimento }\end{array}$} & \multicolumn{4}{|c|}{ Período de armazenamento (dias) } \\
\hline & & 30 & 60 & 90 & 120 \\
\hline \multirow[t]{5}{*}{ Número de raízes } & AM & $8,63 \mathrm{aA}$ & $2,36 \mathrm{bB}$ & $1,46 b C$ & $0,00 \mathrm{bA}$ \\
\hline & PV & $9,30 \mathrm{aA}$ & $9,63 \mathrm{abA}$ & $11,06 \mathrm{aA}$ & $5,40 \mathrm{bA}$ \\
\hline & PA & $7,70 \mathrm{aA}$ & $5,96 \mathrm{aAB}$ & $4,33 \mathrm{abBC}$ & $0,03 \mathrm{bA}$ \\
\hline & SP & $12,76 \mathrm{aA}$ & $5,70 \mathrm{bAB}$ & 7,93abAB & $2,86 \mathrm{bA}$ \\
\hline & SR & $9,93 \mathrm{aA}$ & $3,23 \mathrm{bB}$ & $0,53 \mathrm{bC}$ & $0,00 \mathrm{bA}$ \\
\hline \multirow[t]{5}{*}{ Massa Seca (g) } & AM & $1,59 \mathrm{aB}$ & $0,59 \mathrm{abB}$ & $0,11 \mathrm{bB}$ & $0,00 \mathrm{bA}$ \\
\hline & PV & $1,52 \mathrm{aB}$ & $2,01 \mathrm{aA}$ & $1,63 \mathrm{aA}$ & $0,91 \mathrm{aA}$ \\
\hline & PA & $1,52 \mathrm{aB}$ & $1,14 \mathrm{aAB}$ & $0,76 \mathrm{abAB}$ & $0,00 \mathrm{bA}$ \\
\hline & SP & $3,25 \mathrm{aA}$ & $0,98 \mathrm{bcAB}$ & $1,86 \mathrm{bA}$ & $0,39 \mathrm{cA}$ \\
\hline & SR & $1,50 \mathrm{aB}$ & $0,55 \mathrm{abB}$ & $0,05 \mathrm{bB}$ & $0,00 \mathrm{bA}$ \\
\hline \multirow[t]{5}{*}{ Massa Fresca (g) } & $\mathrm{AM}$ & $0,29 \mathrm{aB}$ & $0,07 \mathrm{abB}$ & $0,02 \mathrm{bCB}$ & $0,00 \mathrm{bA}$ \\
\hline & PV & $0,27 \mathrm{aB}$ & $0,34 \mathrm{aA}$ & $0,41 \mathrm{aA}$ & $0,22 \mathrm{aA}$ \\
\hline & PA & $0,25 \mathrm{aB}$ & $0,20 \mathrm{abAB}$ & $0,13 \mathrm{aBCD}$ & $0,00 \mathrm{bA}$ \\
\hline & SP & $0,54 \mathrm{aA}$ & $0,15 \mathrm{bAB}$ & $0,31 \mathrm{bAB}$ & $0,12 \mathrm{bA}$ \\
\hline & SR & $0,27 \mathrm{aB}$ & $0,07 \mathrm{abB}$ & $0,00 \mathrm{bD}$ & $0,00 \mathrm{bA}$ \\
\hline
\end{tabular}

AM - amido de mandioca; PV - parafina; PA- parafina no ápice; SP - saco plástico; SR - sem recobrimento.

Médias seguidas de mesma letra (letras minúsculas na horizontal; letras maiúsculas na vertical) não diferem entre si ao nível de 5\% de probabilidade pelo Teste de Tukey. 